\section{BRAZIULIAN JOURNAL}

OF MEDICAL AND BIOLOGICAL RESFARCH

www.bjournal.com.br
ISSN 0100-879X

Volume 43 (4) 268-380 April 2011

BIOMEDICAL SCIENCES

AND

CLINICAL INVESTIGATION

Braz J Med Biol Res, April 2011, Volume 44(4) 291-296

doi: 10.1590/S0100-879X2011007500029

\title{
Prevalence of the STK15 F31I polymorphism and its relationship with mammographic density
}

J. Giacomazzi, E. Aguiar, E.I. Palmero, A.V. Schmidt, G. Skonieski, D. Duarte Filho, H. Bock, M.L.

Saraiva-Pereira, L. Schuler-Faccini, S.A. Camey, M. Caleffi, R. Giugliani and P. Ashton-Prolla

The Brazilian Journal of Medical and Biological Research is partially financed by

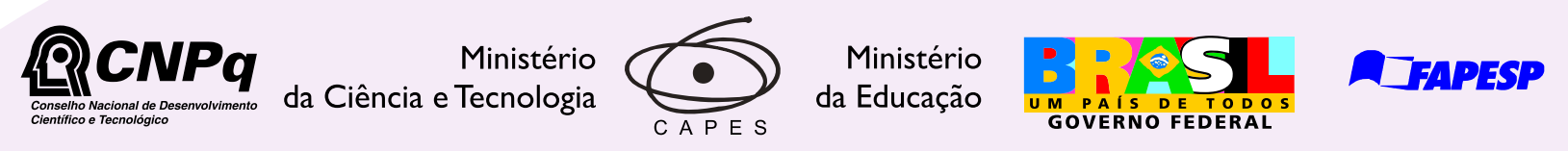

Institutional Sponsors
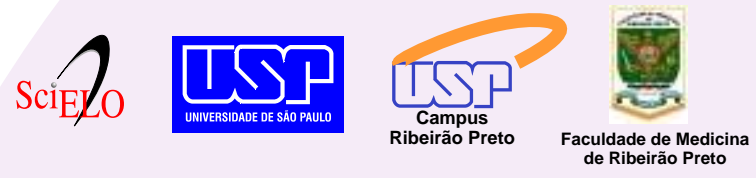
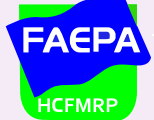

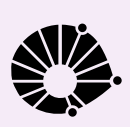

$\oplus$ SHIMADZU

GE Healthcare
Hotsite of proteomics metabolomics developped by:

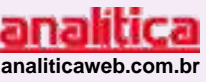

Thermo SCIEN T IFIC 


\title{
Prevalence of the STK15 F31/ polymorphism and its relationship with mammographic density
}

\author{
J. Giacomazzi ${ }^{1,5,8}$, E. Aguiar ${ }^{1,5,8}$, E.I. Palmero $1,5,8$, A.V. Schmidt ${ }^{9}$, G. Skonieski 8 , \\ D. Duarte Filho ${ }^{8}$, H. Bock ${ }^{6}$, M.L. Saraiva-Pereira $3,6,7$, L. Schuler-Faccini4,7, \\ S.A. Camey², M. Caleffi ${ }^{8}$, R. Giugliani ${ }^{1,4,6,7}$ and P. Ashton-Prolla1,4,5,7,8
}

1Programa de Pós Graduação em Medicina: Ciências Médicas, Universidade Federal do Rio Grande do Sul, Porto Alegre, RS, Brasil Departamentos de ${ }^{2}$ Estatística, ${ }^{3}$ Bioquímica e ${ }^{4}$ Genética, Universidade Federal do Rio Grande do Sul, Porto Alegre, RS, Brasil ${ }^{5}$ Laboratório de Medicina Genômica, ${ }^{6}$ Laboratório de Identificação Genética e ${ }^{7}$ Serviço de Genética Médica, Hospital de Clínicas de Porto Alegre, Porto Alegre, RS, Brasil 8 Núcleo Mama Porto Alegre, Associação Hospitalar Moinhos de Vento, Porto Alegre, RS, Brasil ${ }^{9}$ Curso de Graduação em Estatística, Universidade Federal do Rio Grande do Sul, Porto Alegre, RS, Brasil

\begin{abstract}
Several studies have identified the single nucleotide polymorphism STK15 F31/ as a low-penetrance risk allele for breast cancer, but its prevalence and risk association in the Brazilian population have not been determined. The goal of this study was to identify the frequency of this polymorphism in the Brazilian setting. Considering the high degree of admixture of our population, it is of fundamental importance to validate the results already reported in the literature and also to verify the relationship between this variant and breast cancer risk. A total of 750 women without breast cancer were genotyped using the TaqMan PCR assay for STK15 F31/ polymorphism. Clinical information was obtained from review of the medical records and mammographic density from the images obtained using the BI-RADS System. The estimated risk of developing cancer was calculated according to the Gail model. The genotypic frequencies observed in this study were $4.5,38.7$, and $56.6 \%$, respectively, for the STK15 F31I $A A, A T$ and $T T$ genotypes. The $A T$ and $A A$ genotypes were encountered significantly more often in premenopausal women with moderately dense, dense and heterogeneously dense breast tissue $(P=0.023)$. In addition, the presence of the TT genotype was significantly associated with age at menarche $\geq 12$ years $(P=0.023)$. High mammographic density, associated with increased breast cancer risk, was encountered more frequently in premenopausal women with the risk genotypes STK15 F31I $A A$ and $A T$. The genotypic frequencies observed in our Brazilian sample were similar to those described in other predominantly European populations.
\end{abstract}

Key words: STK15 F31/ polymorphism; Breast cancer risk; Mammographic density

\section{Introduction}

Breast cancer $(B C)$ is a significant public health problem in South America, being the most common malignancy among women. In Brazil, BC incidence and mortality rates continue to rise despite significant efforts to establish mammographic screening programs across the country (1).

Southern Brazilian states have particularly high incidence rates, in the range of most countries in Europe and North America, and this is likely a consequence of life style among women in this region (e.g., decreasing number of term pregnancies, significant prevalence of overweight and obesity across age groups, increasing use of hormone replacement therapy) (2).

Other factors should also be considered, such as the influence of environmental factors and the genetic background of the population. The region has received the highest proportion of European immigrants during the last two centuries compared to other regions in Brazil $(2,3)$.

Correspondence: P. Ashton-Prolla, Departamento de Genética, UFRGS e Serviços de Genética Médica e Centro de Pesquisa Experimental, Hospital de Clínicas de Porto Alegre, Rua Ramiro Barcelos, 2350, 90035-903 Porto Alegre, RS, Brasil. Fax: +55-51-3359-8010. E-mail: pprolla@hcpa.ufrgs.br 
Several genetic polymorphisms associated with an increased risk of $B C$ have been identified in genes involved in hormone metabolism, carcinogen metabolism as well as in some high penetrance genes such as TP53 (4).

Polymorphisms in the STK15 gene have been recently described and an association with $\mathrm{BC}$ risk has been proposed. The STK15 gene (also known as AURKA, STK6, and $B T A K$ ) encodes Aurora- $A$, a serine-threonine kinase that acts as a key regulator of mitotic chromosome segregation and is particularly involved in the passage from the $G_{2}$ to the $M$ phase of the cell cycle $(5,6)$. Defects in chromatid segregation cause genetic instability, a condition that is clearly associated with tumorigenesis (7). Due to its regulatory function in the cell cycle, the STK15 gene has been suggested to be a potential cancer susceptibility gene. A single nucleotide polymorphism (SNP) at nucleotide $91, T>A$, results in the substitution of phenylalanine by isoleucine in codon $31(F 31 /)$ and affects the function of the STK15 gene (6).

The first study reporting an association of the STK15 F31/ polymorphism with $\mathrm{BC}$ described a significantly increased risk $(\mathrm{OR}=1.76,95 \% \mathrm{Cl}=1.29-2.12)$ in women with the AA STK15 F31/ genotype (8). A second study reported an increase in $\mathrm{BC}$ risk in association with both the AT STK15 F31I (OR $=1.3,95 \% \mathrm{Cl}=1.0-1.7)$ and $A A$ STK15 F31/ genotypes (OR = 1.2, 95\%Cl = 0.9-1.6) (9). An association between overweight (body mass index, $\mathrm{BMI} \geq 25$ ) and these genotypes was also described (OR $=3.3,95 \% \mathrm{Cl}=1.4-7.7)$ for the AT STK15 F31/ genotype and for the AA STK15 F31/ genotype $(\mathrm{OR}=4.1,95 \% \mathrm{Cl}$ $=1.7-9.8)$. The same authors suggested that the association of STK15 genotype, BC risk and increased BMI could be further modified by factors related to increased endogenous exposure to estrogen, including enhanced peripheral metabolism, early menarche, late menopause, and later age at first childbirth. However, additional studies have reported an association between the AA STK15 F31I genotype and overall $B C$ risk in relation to BMI. Results are conflicting, with increased risk being associated with postmenopausal women with and without an increased BMI (9-11).

No association between the STK15 F31/polymorphism and mammographic density was identified in the literature. The mammographic density (radiological breast density) is influenced by the hormonal changes that occur throughout the life of women and is considered to be one of the most important independent risk factor for breast cancer (12). Hormonal changes reflect persistent differences in cell cycle regulators, signal transduction pathways, transcription factors, and other unknown regulatory molecules.

Thus, the objective of the present study was to determine the allelic and genotypic frequencies of the STK15 F31/ polymorphism in 750 healthy women and also to investigate the relationship of this polymorphism with breast cancer risk factors, including mammographic density.

\section{Material and Methods}

\section{Study population and data collection}

A consecutive and unselected sample of 750 breast cancer-unaffected women (ages 40-69 years) enrolled in a mammography screening program in the city of Porto Alegre (Núcleo Mama Porto Alegre - NMPOA Cohort) was recruited for this study during routine mammographic visits for 4 months $(13,14)$. Study approval was obtained from the Ethics Committees of the participating institutions, Hospital de Clínicas de Porto Alegre and Associação Hospitalar Moinhos de Vento, and all individuals recruited for the study gave written informed consent. Demographic and clinical information as well as results from mammographic screening were obtained from chart review. We also started a prospective DNA collection of all breast cancer cases identified within the program and present here preliminary results of the analysis of the first 39 cases recruited.

\section{Study variables}

Study variables included age at recruitment, age at first childbirth, age at menarche and menopause, parity, BMI (classified into 4 categories: <18.5; $\geq 18.5-24.99 ; 25-$ 29.99 ; $\geq 30$ ), race (white or non-white, assessed by selfclassification), results of the mammographic examination and mammographic density (using the BI-RADS and breast density categories of the American College of Radiology 1998), previous breast biopsies, use of hormone replacement therapy (HRT) and/or oral contraceptives, estimated 5-year risk (Gail 5-years) and estimated lifetime risk of developing cancer according to the Gail model $(15,16)$.

\section{Polymorphism analysis}

Genomic DNA was obtained from peripheral blood samples using standard methods (17). Genotyping was performed using the TaqMan PCR assay for STK15 F31/ polymorphism (rs2273535, C_25623289_10 Applied Biosystems, USA), with fluorescent minor groove binding probes. Analyses were performed using an ABI 7500 real-time PCR system (Applied Biosystems), and results were analyzed with the Sequence Detection software v 1.4 (Applied Biosystems).

\section{Statistical analysis}

SPSS version 14.0 was used for data handling and statistical analyses. For descriptive analysis, categorical variables were described by their absolute and/or relative frequencies and quantitative variables are reported as means $\pm \mathrm{SD}$. For analytical statistics, the $t$-test for independent variables and ANOVA were used to compare the mean values of the quantitative variables. The existence of an association between categorical variables was examined by the chi-square test. The level of significance of 0.05 was adopted in all analyses. Comparative analysis of genotypic frequencies between this and other studies was done using the WINPEPI package (PEPI-for-Windows) (18). 


\section{Results}

Data regarding the $\mathrm{BC}$ risk factors identified in the sample are presented in Table 1. Mean age ( $\pm S D)$ at inclu- sion of the women enrolled in the present study was $51 \pm$ 7.6 years, $420(56.0 \%)$ women were postmenopausal, and the mean estimated lifetime risk of developing $\mathrm{BC}$ in the overall sample using the Gail model was $7.8 \pm 3.3 \%$.

Table 1. Clinical characteristics of the sample studied $(N=750)$.

\begin{tabular}{|c|c|c|}
\hline Variable & $N(\%)$ & Mean \pm SD \\
\hline Age at assessment (years) & - & $51.0 \pm 7.6$ \\
\hline Age at menarche (years) & - & $12.8 \pm 1.8$ \\
\hline Age at first childbirth (years) & - & $22.0 \pm 5.3$ \\
\hline Nulliparous & $31(4.13)$ & - \\
\hline Postmenopausal & $421(56.1)$ & - \\
\hline Age at menopause (years) & - & $46.9 \pm 5.5$ \\
\hline Use of hormone replacement therapy & $118(28.1)$ & - \\
\hline Body mass index $\left(\mathrm{kg} / \mathrm{m}^{2}\right)$ & - & $29.6 \pm 5.8$ \\
\hline$<18.5$ & $6(0.8)$ & - \\
\hline$\geq 18.5-24.99$ & $158(21.1)$ & - \\
\hline $25-29.99$ & $273(36.4)$ & - \\
\hline$\geq 30$ & $308(41.1)$ & - \\
\hline Family history of breast cancer* & $100(13.3 \%)$ & - \\
\hline \multicolumn{3}{|l|}{ Mammographic examination } \\
\hline BI-RADS 0 & $4(0.53)$ & \\
\hline BI-RADS 1 or BI-RADS 2 & $732(97.6)$ & \\
\hline BI-RADS 3 & $9(1.2)$ & \\
\hline BI-RADS 4 & $5(0.67)$ & \\
\hline \multicolumn{3}{|l|}{ Mammographic density } \\
\hline Fatty breast tissue or moderately fatty breast tissue & $426(56.8)$ & - \\
\hline Moderately dense, dense or heterogeneously dense tissue & $324(43.2)$ & - \\
\hline Estimated lifetime risk of developing breast cancer (\%), using the Gail model & - & $7.8 \pm 3.3$ \\
\hline Previous breast biopsy & $40(5.3)$ & - \\
\hline
\end{tabular}

*There was considered to be a family history $(\mathrm{FH})$ of breast cancer if the answer to one of these questions was positive: 1) $\mathrm{FH}$ of breast or ovarian cancer in 1st degree relatives; 2) $\mathrm{FH}$ of bilateral breast cancer; 3) any man in the family with breast cancer; 4) any woman in the family with breast and ovarian cancer; 5) any woman in the family with breast cancer before the age of 50 years; 6 ) two or more relatives with breast and/or ovarian cancer; 7 ) two or more relatives with breast and/or bowel cancer.

Table 2. Genotypic and allelic frequencies of the STK15 F31/ polymorphism in the overall sample $(\mathrm{N}=750)$, and in white $(\mathrm{N}=599)$ and non-white women $(\mathrm{N}=151)$.

\begin{tabular}{|c|c|c|c|c|c|c|}
\hline & \multicolumn{3}{|c|}{ Genotypic frequencies } & \multicolumn{2}{|c|}{ Allelic frequencies } & \multirow[t]{2}{*}{$\mathrm{H}-\mathrm{W}$} \\
\hline & $A A$ & $A T$ & $T T$ & $A$ & $T$ & \\
\hline Overall & $34(4.5)$ & $291(38.7)$ & $425(56.6)$ & 0.24 & 0.76 & 3.23 \\
\hline White & $25(4.2)$ & 234 (39) & $340(56.8)$ & 0.24 & 0.76 & 3.82 \\
\hline Non-white & $9(5.9)$ & $57(37.8)$ & $85(56.3)$ & 0.25 & 0.75 & 0.02 \\
\hline
\end{tabular}

Data are reported as number of patients with percent in parentheses. $\mathrm{H}-\mathrm{W}=$ Hardy-Weinberg equilibrium. $\mathrm{P}=0.91$ for white women compared to non-white women (chi-square test). Preliminary analysis of the STK15 F31/ polymorphism identified in cancer patients within this program showed different allelic frequencies compared to breast cancer-unaffected women. The genotype frequencies encountered in the first 39 cases recruited were $A A=22$ patients $(56.1 \%)$, $A T=13$ patients $(33.4 \%)$ and $T T=4$ patients $(10.2 \%)$ 
Table 3. Genotypic and allelic frequencies of the STK15 F31/ polymorphism in breast cancer-unaffected women in the present study and in other studies.

\begin{tabular}{|c|c|c|c|c|c|c|c|c|}
\hline \multicolumn{3}{|c|}{ Genotypic frequencies } & \multicolumn{2}{|c|}{ Allelic frequencies } & \multirow[t]{2}{*}{$\mathrm{N}$} & \multirow[t]{2}{*}{$\mathrm{P}$} & \multirow[t]{2}{*}{ Country } & \multirow[t]{2}{*}{ References } \\
\hline AA & AT & TT & $A$ & $\mathrm{~T}$ & & & & \\
\hline $34(4.5)$ & $291(38.7)$ & $425(56.7)$ & 0.24 & 0.76 & 750 & & Brazil & Present study \\
\hline $192(36.9)$ & $262(50.4)$ & $66(12.7)$ & 0.62 & 0.38 & 520 & $<0.001$ & China & 8 \\
\hline $81(42.4)$ & $85(44.5)$ & $25(13.1)$ & 0.65 & 0.35 & 191 & $<0.001$ & China & 8 \\
\hline $534(45.0)$ & $503(42.4)$ & $149(12.6)$ & 0.66 & 0.34 & 1186 & $<0.001$ & China & 9 \\
\hline $886(45.0)$ & $887(45.0)$ & $196(10.0)$ & 0.68 & 0.32 & 1969 & $<0.001$ & Taiwan & 21 \\
\hline $31(3.7)$ & $283(34.1)$ & $516(62.2)$ & 0.21 & 0.79 & 830 & 0.082 & United States & 11 \\
\hline $21(4.7)$ & $148(33.0)$ & $279(62.3)$ & 0.21 & 0.79 & 448 & 0.131 & United States & 6 \\
\hline $56(5.5)$ & $332(32.3)$ & $639(62.2)$ & 0.22 & 0.78 & 1027 & 0.017 & United States & 20 \\
\hline $485(59.2)$ & $287(35.0)$ & $47(5.8)$ & 0.77 & 0.23 & 819 & $<0.001$ & Germany & 27 \\
\hline
\end{tabular}

Genotypic frequencies are reported as number with percent in parentheses and allelic frequencies as percent.

The allelic and genotypic frequencies of the STK 15 F31I polymorphism are presented in Table 2. The distribution of genotypes for this polymorphism in the overall sample, as well as that of the self-denominated groups of white and non-white women was consistent with Hardy-Weinberg equilibrium (H-W: $3.22,3.83,0.02$, respectively). There were no significant differences in observed allelic and genotypic frequencies between white and non-white women $(P>0.05)$.

The STK15 F31/ AT and AA genotypes were encountered significantly more often in premenopausal women with moderately dense, dense and heterogeneously dense breast tissue $(P=0.023)$. In addition, the presence of the STK15 F31/ TT genotype was significantly associated with age at menarche $\geq 12$ years $(P=0.023)$. No significant associations with other breast cancer risk factors were identified.

Interestingly, preliminary results of the first $39 \mathrm{BC}$ patients identified within this cohort of 750 women showed that the genotypic frequencies were significantly different between cases and controls (especially for the $T T$ and $A A$ genotypes). This difference is striking and in favor of a role of STK15 as an independent risk factor for BC as previously suggested by other investigators. Assessment of this polymorphism in a larger series of $\mathrm{BC}$ patients from the same community is needed, however, to confirm these results.

\section{Discussion}

Several studies have now identified the STK15 F31I polymorphism as a low-penetrance risk allele for BC, but its association with clinical characteristics or with mammographic density in a Brazilian population has not been determined. Compelled by a possible association of the STK15
F31/ polymorphism with these variables, we performed the present study in a population-based sample of women submitted to mammographic screening from a geographic area of Brazil with high $\mathrm{BC}$ incidence rates.

The genotypic frequencies encountered in this study were similar to those described in other predominantly European populations $(6,11,19,20)$ and significantly distinct from those observed among Asians (Table 3). This is not unexpected because, although the contemporary Brazilian population is highly admixed, there is a predominance of European alleles, especially in the formation of the genetic pool of Southern Brazil where this study was carried out. Price et al. (22), for instance, have estimated that African and European ancestry corresponds to 11 and $71 \%$ of the alleles in Brazilian individuals and Alves-Silva et al. (23) described a major contribution of European alleles to both mitochondrial (66\%) and nuclear (79\%) DNA in populations from Southern Brazil. An interesting observation is that the frequency of homozygotes for the STK15 F31/ A allele (risk genotype $A A$ ) is 7 -fold higher in the Asian (Chinese) populations studied so far than in the sample studied here and other European populations. In Chinese women, BC incidence rates are significantly lower than those observed in Western countries and in Brazil (24).

In addition, the presence of the STK15 F31/TT genotype was significantly associated with age at menarche $\geq 12$ years $(P=0.023)$. No significant association was found between the STK 15 F31/polymorphism and age at menopause, age at first childbirth, BMI or use of HRT.

We also investigated a possible association between the STK 15 F31/ polymorphism and indicators of prolonged estrogen exposure. Breast cancer is a hormone-related tumor, and it is well established that sex hormones increase breast cancer risk (and modify the mammographic density) by increasing proliferation of breast epithelial cells. It has 
also been suggested that loss of function of certain STK15 alleles could potentially be enhanced in women with higher exposure, either endogenous or exogenous, to the mitogenic influence of estrogen (25-27). The STK15 F31/ risk genotypes $A T$ and $A A$ were encountered significantly more often in premenopausal women with moderately dense, dense and heterogeneously dense breast tissue $(P=0.023)$.

Replication errors and genetic damage during cell division, if not corrected, may lead to breast cancer. In experimental studies, overexpression of STK15 in non-malignant cultured cells leads to centrosome amplification, chromosome instability, transformation and the ability to induce tumors. In addition, amplification and/or overexpression of STK15 has been reported in cancer cell lines and in several human tumors, including breast cancer. Although the functional significance of allele $A$ of the STK15 F31/ polymorphism has not been fully determined, some publications have reported that this allele is associated with accelerated growth and proliferation of tumor cells in culture. In the present study, we suggest that women with the $A$ allele, associated with increased expression of STK15, experience high proliferation of breast epithelial cells and this would be the biologic rationale for the observed increase in breast density. The increased risk for breast cancer associated with higher breast density could be related to the biologic observation of accelerated cell proliferation and/or due to the difficulties in assessing dense breast tissue by conventional screening methods (i.e., mammography) $(9,25-27)$.

Since mammographic density directly reflects the status of breast parenchyma and stroma, it is reasonable to suggest that increased breast density may be associated with increased breast cancer risk due to an increased number of epithelial cells and/or an increased proliferative state of these cells. In this setting, the $A T$ and $A A$ genotypes of STK15 polymorphism F31/ could be associated with increased breast cancer risk through increased expression of the gene. Multiple factors influence the mammographic pattern, including age, reproductive history, hormone levels, and body constitution. In this study, we demonstrate that a genetic polymorphism is associated with increased breast density. The genetic determinants of breast density are being extensively studied and this is a promising area of research, since identification of an "intrinsic" determinant of increased breast density could also potentially be a risk factor for breast cancer.

Further investigation of the STK15 F31/ polymorphism in other populations and especially, in case-control studies of women with or without breast cancer are necessary to establish whether it has a role as a genetic risk factor for this disease.

We conclude that the genotypic frequencies observed in the sample of 750 healthy women from Southern Brazil studied here were similar to those described in other predominantly European populations. High mammographic density was encountered more frequently in premenopausal women with the STK15 F31/ risk genotypes $A A$ and $A T$, suggesting that this polymorphism has a phenotypic effect and may play an important role in breast cancer risk determination. Furthermore, this study adds to current knowledge that genetic determinants of mammographic density may be useful in building multigenic models for predicting breast cancer risk. Finally, if confirmed, the associations between STK15 F31/ risk genotypes and high mammographic density in premenopausal women could have important implications for mammographic screening strategies in this and other populations. Additional case-control studies are necessary to confirm the findings described here.

\section{Acknowledgments}

The Núcleo Mama (NMAMA) Cohort, from which the patients derive, is maintained by Associação Hospitalar Moinhos de Vento in partnership with Instituto da Mama do Rio Grande do Sul and the Municipal Health Agency from Porto Alegre. The authors are indebted to Ademar Bedin Júnior, Fávio Marcel Telis Gonzalez, Luciano Artico, Bernardete Weber, Karen Barboza de Pereira, and the NMPOA team for their help with the recruitment of the patients included in this study. Research supported in part by CNPq (Edital MCT-CNPq/MS-SCTIE-DECIT/CT-Saude \#06/2005, protocol \#400949/2005-9), Susan G. Komen for the Cure (population-specific grant \#POP0403033), and Fundo de Incentivo à Pesquisa do Hospital de Clínicas de Porto Alegre (FIPE/HCPA, Brazil, \#05-182). P. Ashton-Prolla is the recipient of a Productivity fellowship from $\mathrm{CNPq}$ and J. Giacomazzi received a fellowship from CAPES.

\section{References}

1. World Health Organization Database. [http://www.who.int/ infobase].

2. McPherson K, Steel CM, Dixon JM. ABC of breast diseases. Breast cancer-epidemiology, risk factors, and genetics. BMJ 2000; 321: 624-628.

3. Schwartsmann G. Breast cancer in South America: challenges to improve early detection and medical management of a public health problem. J Clin Oncol 2001; 19: 118S-124S.

4. Dunning AM, Healey CS, Pharoah PD, Teare MD, Ponder
BA, Easton DF. A systematic review of genetic polymorphisms and breast cancer risk. Cancer Epidemiol Biomarkers Prev 1999; 8: 843-854.

5. Dutertre S, Descamps S, Prigent C. On the role of Aurora-A in centrosome function. Oncogene 2002; 21: 6175-6183.

6. Ewart-Toland A, Briassouli P, de Koning JP, Mao JH, Yuan $J$, Chan F, et al. Identification of Stk6/STK15 as a candidate low-penetrance tumor-susceptibility gene in mouse and human. Nat Genet 2003; 34: 403-412. 
7. Lengauer C, Kinzler KW, Vogelstein B. Genetic instabilities in human cancers. Nature 1998; 396: 643-649.

8. Sun T, Miao X, Wang J, Tan W, Zhou Y, Yu C, et al. Functional Phe31lle polymorphism in Aurora A and risk of breast carcinoma. Carcinogenesis 2004; 25: 2225-2230.

9. Dai Q, Cai QY, Shu XO, Ewart-Toland A, Wen WQ, Balmain $A$, et al. Synergistic effects of STK15 gene polymorphisms and endogenous estrogen exposure in the risk of breast cancer. Cancer Epidemiol Biomarkers Prev 2004; 13: 2065 2070.

10. Cox DG, Hankinson SE, Hunter DJ. Polymorphisms of the AURKA (STK15/Aurora Kinase) Gene and Breast Cancer Risk (United States). Cancer Causes Control 2006; 17: 8183.

11. Egan KM, Newcomb PA, Ambrosone CB, Trentham-Dietz A, Titus-Ernstoff L, Hampton JM, et al. STK15 polymorphism and breast cancer risk in a population-based study. Carcinogenesis 2004; 25: 2149-2153. Erratum: Carcinogenesis 2005; 26: 701.

12. Chambo D, Kemp C, Costa AM, Souza NC, Guerreiro da Silva I. Polymorphism in CYP17, GSTM1 and the progesterone receptor genes and its relationship with mammographic density. Braz J Med Biol Res 2009; 42: 323-329.

13. Caleffi M, Ashton-Prolla P, Weber B, Zignani JM, Dias EC, Antunes LP, et al. Breast cancer screening in 10.000 women of an underserved population in South Brazil: the NMAMAPOA cohort. J Clin Oncol 2005; 23: 877.

14. Smith RA, Caleffi M, Albert US, Chen TH, Duffy SW, Franceschi D, et al. Breast cancer in limited-resource countries: early detection and access to care. Breast J 2006; 12 (Suppl 1): S16-S26.

15. American College of Radiology. Illustrated breast imaging reporting and data system (BIRADS). Reston: American College of Radiology; 1998.

16. Gail MH, Brinton LA, Byar DP, Corle DK, Green SB, Schairer $\mathrm{C}$, et al. Projecting individualized probabilities of developing breast cancer for white females who are being examined annually. J Natl Cancer Inst 1989; 81: 1879-1886.
17. Miller SA, Dykes DD, Polesky HF. A simple salting out procedure for extracting DNA from human nucleated cells. Nucleic Acids Res 1988; 16: 1215.

18. Abramson JH. WINPEPI (PEPI-for-Windows): computer programs for epidemiologists. Epidemiol Perspect Innov $2004 ; 1: 6$

19. Fletcher O, Johnson N, Palles C, dos Santos Silva I, McCormack $\mathrm{V}$, Whittaker J, et al. Inconsistent association between the STK15 F31I genetic polymorphism and breast cancer risk. J Natl Cancer Inst 2006; 98: 1014-1018.

20. Gu J, Gong Y, Huang M, Lu C, Spitz MR, Wu X. Polymorphisms of STK15 (Aurora-A) gene and lung cancer risk in Caucasians. Carcinogenesis 2007; 28: 350-355.

21. Lo YL, Yu JC, Chen ST, Yang HC, Fann CS, Mau YC, et al. Breast cancer risk associated with genotypic polymorphism of the mitosis-regulating gene Aurora-A/STK15/BTAK. Int $J$ Cancer 2005; 115: 276-283.

22. Price AL, Patterson N, Yu F, Cox DR, Waliszewska A, McDonald GJ, et al. A genomewide admixture map for Latino populations. Am J Hum Genet 2007; 80: 1024-1036.

23. Alves-Silva J, da Silva Santos M, Guimaraes PE, Ferreira AC, Bandelt HJ, Pena SD, et al. The ancestry of Brazilian mtDNA lineages. Am J Hum Genet 2000; 67: 444-461.

24. Tavassoli FA, Devillee P. World Health Organization. Classification of tumour. Pathology and genetics of tumours of the breast and female genital organs. Lyon: IARC Press; 2003.

25. Persson I. Estrogens in the causation of breast, endometrial and ovarian cancers - evidence and hypotheses from epidemiological findings. J Steroid Biochem Mol Biol 2000; 74 : 357-364.

26. Dicioccio RA, Song $H$, Waterfall $C$, Kimura MT, Nagase $H$, McGuire V, et al. STK15 polymorphisms and association with risk of invasive ovarian cancer. Cancer Epidemiol Biomarkers Prev 2004; 13: 1589-1594.

27. Tchatchou S, Wirtenberger M, Hemminki K, Sutter C, Meindl A, Wappenschmidt B, et al. Aurora kinases A and B and familial breast cancer risk. Cancer Lett 2007; 247: 266-272. 